
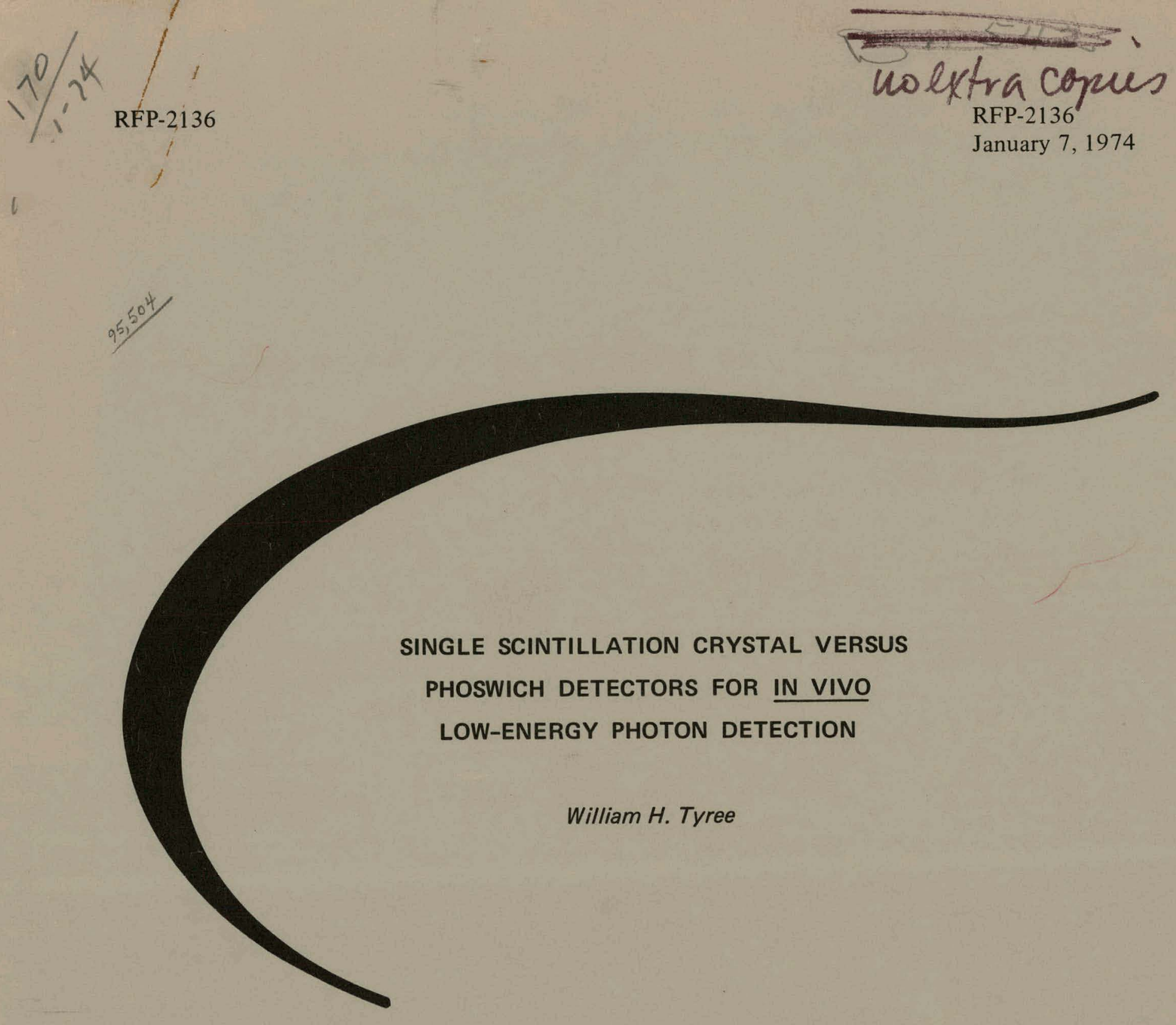

\title{
SINGLE SCINTILLATION CRYSTAL VERSUS \\ PHOSWICH DETECTORS FOR IN VIVO \\ LOW-ENERGY PHOTON DETECTION
}

William H. Tyree

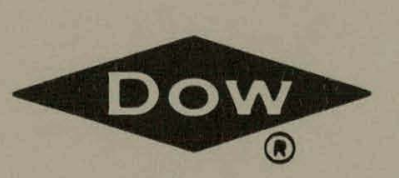

DOW CHEMICAL U.S.A. ROCKY FLATS DIVISION

P. O. BOX 888

GOLDEN, COLORADO 80401

U. S. ATOMIC ENERGY COMMISSION CONTRACT AT(29-1)-1106 


\section{DISCLAIMER}

This report was prepared as an account of work sponsored by an agency of the United States Government. Neither the United States Government nor any agency Thereof, nor any of their employees, makes any warranty, express or implied, or assumes any legal liability or responsibility for the accuracy, completeness, or usefulness of any information, apparatus, product, or process disclosed, or represents that its use would not infringe privately owned rights. Reference herein to any specific commercial product, process, or service by trade name, trademark, manufacturer, or otherwise does not necessarily constitute or imply its endorsement, recommendation, or favoring by the United States Government or any agency thereof. The views and opinions of authors expressed herein do not necessarily state or reflect those of the United States Government or any agency thereof. 


\section{DISCLAIMER}

Portions of this document may be illegible in electronic image products. Images are produced from the best available original document. 


\section{LEGAL NOTICE}

This repnrt was prepared as an account of work sponsored by the United States Government. Neither the United States nor the United States Atomic Energy Commission, nor any of their employees, nor any of their contractors, subcontractors, or their employees, makes any warranty, expressed or implied, or assumes any legal liability or responsibility for the accuracy, completeness or usefulness of any information, apparatus, product or process disclosed, or represents that its use would not infringe privately owned rights.

Printed in the United States of America

Available from the

National Technical Information Service

U. S. Departuent of Commcrec

Springfield, Virginia 22151

Price: Printed Copy $\$ 4.00$ Microfiche $\$ 1.45$ 


\section{SINGLE SCINTILLATION CRYSTAL VERSUS PHOSWICH DETECTORS FOR IN VIVO LOW-ENERGY PHOTON DETECTION}

William H. Tyree

Product and Health Physics Research ELECTRONICS GROUP

\footnotetext{
NOTICE

This report was prepared as an account of work sponsored by the United States Government. Neither the United States nor the United States Atomic Eutergy Commission, nor any of their employees, nor any of their contractors, subcontractors, or their employees, makes any warranty, express or implied, or assumes any make any wron, ox legal liability or responsihility for the accuracy, completeness or usefulness of any information, apparatus, product or process disclosed, or represents that its use would not infringe privately owned rights.
}

DOW CHEMICAL U.S.A.

ROCKY FLATS DIVISION

P. O. BOX 888

GOLDEN, COLORADO 80401

Prepared under Contract AT(29-1)-1106

for the

Albuquerque Operations Office

U. S. Atomic Energy Commission

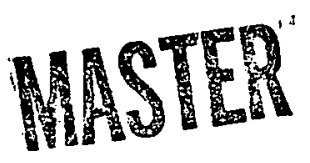


RFP-2136 


\section{CONTENTS}

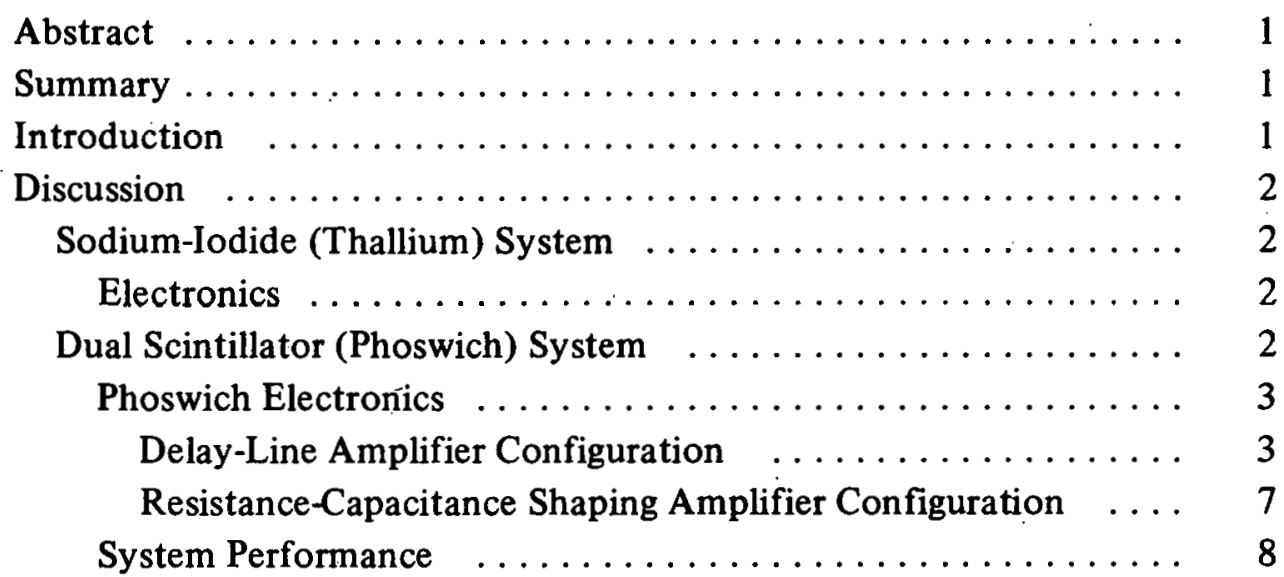


RFP-2136 


\title{
SINGLE SCINTILLATION CRYSTAL VERSUS PHOSWICH DETECTORS FOR
}

\author{
IN VIVO LOW-ENERGY PHOTON DETECTION
}

\author{
William H. Tyree
}

\begin{abstract}
The development of in vivo body-count measurement systems for the detection of lowenergy photons from americium and plutonium has stressed the importance of low background counting rates for better sensitivity. The measurement systems are developed for use in the body-counting facility, which has been in operation at the Rocky Flats Plant, to detect exposurcs in humans from radioactive materials. The facility is in a separate building and houses the body counter which consists of thick steel walls. The detectors within the body counter section are arranged over a table or couch and can be positioned over various parts of the body. of an individual being checked for the presence of radioactive materials.
\end{abstract}

The systems in current use provide an improvement in background counting rates for sodium-iodide thallium detectors with the two-crystal sandwich or Phoswich scintillator. The two types of electronic configurations used with the Phoswich detectors demonstrate improvements in background counting rates over results from a single crystal detector.

Tabulated data comparing the operating parameters of a single crystal and a dual-crystal configuration are included.

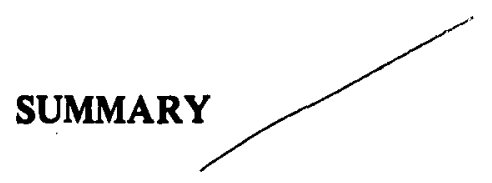

The Phoswich detector system developed for the in vivo detection of plutonium and americium uses a timed coincidence system to produce a coincidence pulse to the input of the analog-to-digital converter $(A D C)$ of the pulse height analyzer.

The system produces a factor of 4 to 5 reduction in room background count for each of the detectors used in the shield with slightly better resolution at full width half maximum (FWHM) than the single crystal sodium-iodide thallium [NaI (Tl)] system.

\begin{abstract}
The
The Phoswich system produces a factor of 3 reduction in human background for each of the detectors inside a steel room for the same source count.

Delay-line amplifiers and resistance-capacitance (R-C) shaped amplifiers were used to produce comparable background data (see illustrations) in spite of the greater time dispersion for the system with the R-C shaping amplifier.
\end{abstract}

\section{INTRODUCTION}

Body counting represents a superior technique for the measurement of radioisotopes deposited in vivo. The use of detectors within massive steel walls for the measureinent of radiation associated with the decay of plutonium-239 and americium-241 has actively been under study at Rocky Flats Plant for the past ten years. The detectors provide good geometry for in vivo applications, but suffer from relatively poor resolution. The poor resolution demands a wide energy summation for any particular photon energy. These summations represent large background counting rates, which limit the effective detector sensitivity.

The single crystal scintillation system has been incorporated into the routine operation at the body-counter facility because of the stability exhibited by the detectors during use, and also the ease of maintenance for continued operation.

The system described herein includes a two-crystal sandwich or Phoswich detector which provides a capability of separating the pulses produced in the thin sodium-iodide thallium [NaI (T1)] crystal. The system permits only those pulses which are the result of total energy deposition in the $\mathrm{NaI}$ (T1) to pass through the electronics timing system to the input of the analog-to-digital converter (ADC). 
The two types of electronic configurations used in the body-counter facility are compared with the single crystal detector and demonstrate the advantages.

\section{DISCUSSION}

\section{Sodium-Iodide (Thallium) System:}

The single crystal NaI (Tl) scintillator provides a simple, low-cost body counter detection system. The system however has limitations because of poor resolution and produces a relatively high background counting rate.

The detectors in use form an integral line unit having a scintillator diameter of 10.16 centimeters (cm) with a thickness of $0.4 \mathrm{~cm}$. The scintillator output is coupled to the photocathode of a $12.70-\mathrm{cm}$ photomultiplier tube through a $2.54-\mathrm{cm}$ quartz light transmitter. The integral assembly, including scintillator, light transmitter, and phototube assembly, is manufactured by the Harshaw Chemical Company, Cleveland, Ohio.

The entrance window consists of beryllium for transmission of the X-rays resulting from plutonium (Pu) and americium (Am) decay.

The amplifying system includes a preamplifier to provide signal conditioning for transmission over a long coaxial cable. A linear amplifier produces pulse shaping and gain for linear-pulse output amplitudes of up to 10 volts.

The single scintillator detector produces a typical spectrum for an americium source $\left({ }^{241} \mathrm{Am}\right)$ as shown in Figure 1.

\section{Elcctronics}

The block diagram of a typical electronic system for the single scintillator crystal is shown in Figure 2.

Three of these systems are used in each steel shield of the body-counter facility to detect photons emitted from the lung cavities and liver regions of

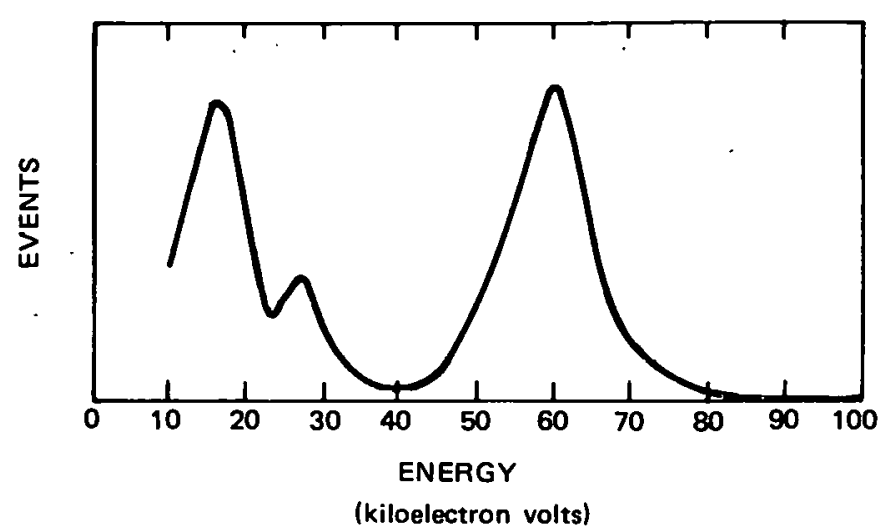

FIGURE 1. Spectrum for Americium-241 Source in Single Crystal Detector ( 10 by 0.4 centimeters).

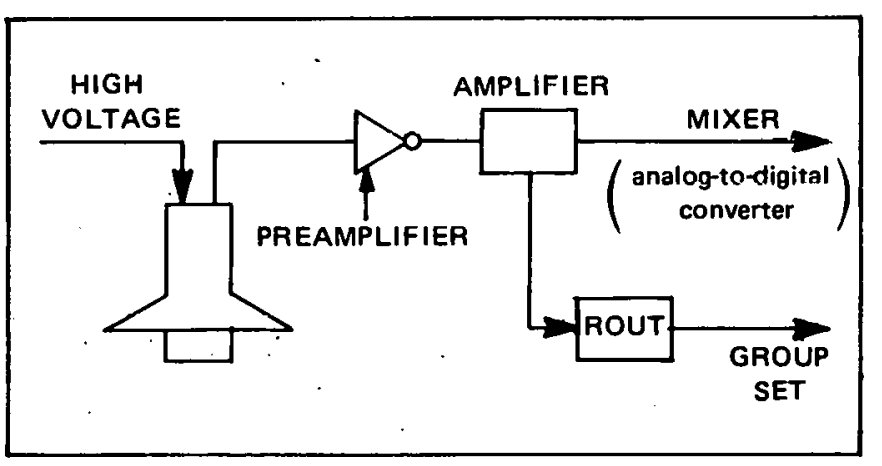

FIGURE 2. Single Crystal Detector System.

a subject. These detectors are operated in a timesharing mode with the resultant spectrum from cach detector stored in separate groups of the pulseheight analyzer memory.

\section{Dual Scintillatox (Phnswirh) System:}

Detectors in one of the steel shields in the bodycounter facility have been modificd to provide lower background cöuninting rates wilh lwu Plıuswicli scintillation detectors in place of the single crystal $\mathrm{NaI}$ (Tl) detectors. The external or physical differences between these two units are noted in Figures 3(a) and (b). The Phoswich units (b) are used for detecting low-energy photon emission from the left and right chest regions (see Figure 4).

The Phoswich detector is composed of two scintillators both $10.16 \mathrm{~cm}$ in diameter. The $\mathrm{NaI}(\mathrm{Tl})$ scintillator is $0.4 \mathrm{~cm}$ thick and is mounted adjacent 


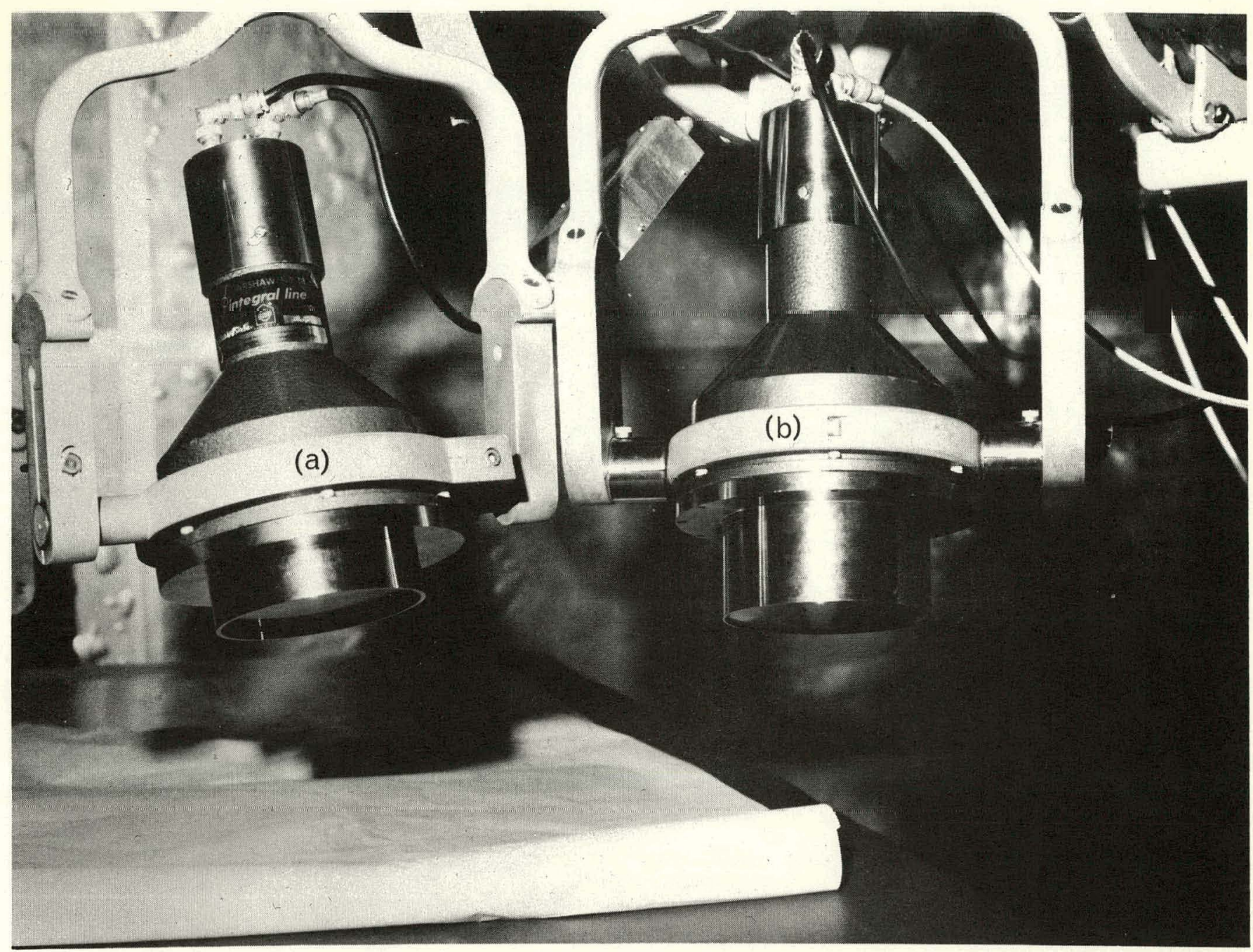

FIGURE 3. Physical Differences between Harshaw Single Crystal (a) and Dual Crystal Scintillators (b).

$17262-5$

to the beryllium entrance window. Cesium-iodide (thallium) [CsI (T1)] is used as the second scintillator and also performs as a light transmitter between the $\mathrm{NaI}(\mathrm{Tl})$ crystal and photomultiplier tube. The CsI (T1) crystal is $5.08 \mathrm{~cm}$ thick.

\section{Phoswich Electronics-}

The detector electronics system required for timing the crossover and determining the coincidence operation of the linear gate to the pulse-height analyzer (PHA) mixer consists of two configurations. (NOTE: The delayed sweep shown in the illustrations was produced by triggering the sweep from a discriminator pulse produced from an undelayed amplifier output signal.)

\section{Delay-Line Amplifier Configuration}

The pulse-width distributions are typical of the $\mathrm{NaI}(\mathrm{Tl})$ and $\mathrm{CsI}(\mathrm{Tl})$ scintillators used with the integral line assemblies. Typical pulse-shape outputs to the timing system from the delay-line amplifier are shown in Figure 5. The Phoswich outputtiming system analyzer with a delay-line amplifier produced the pulse-time distribution shown in Figure 6. 


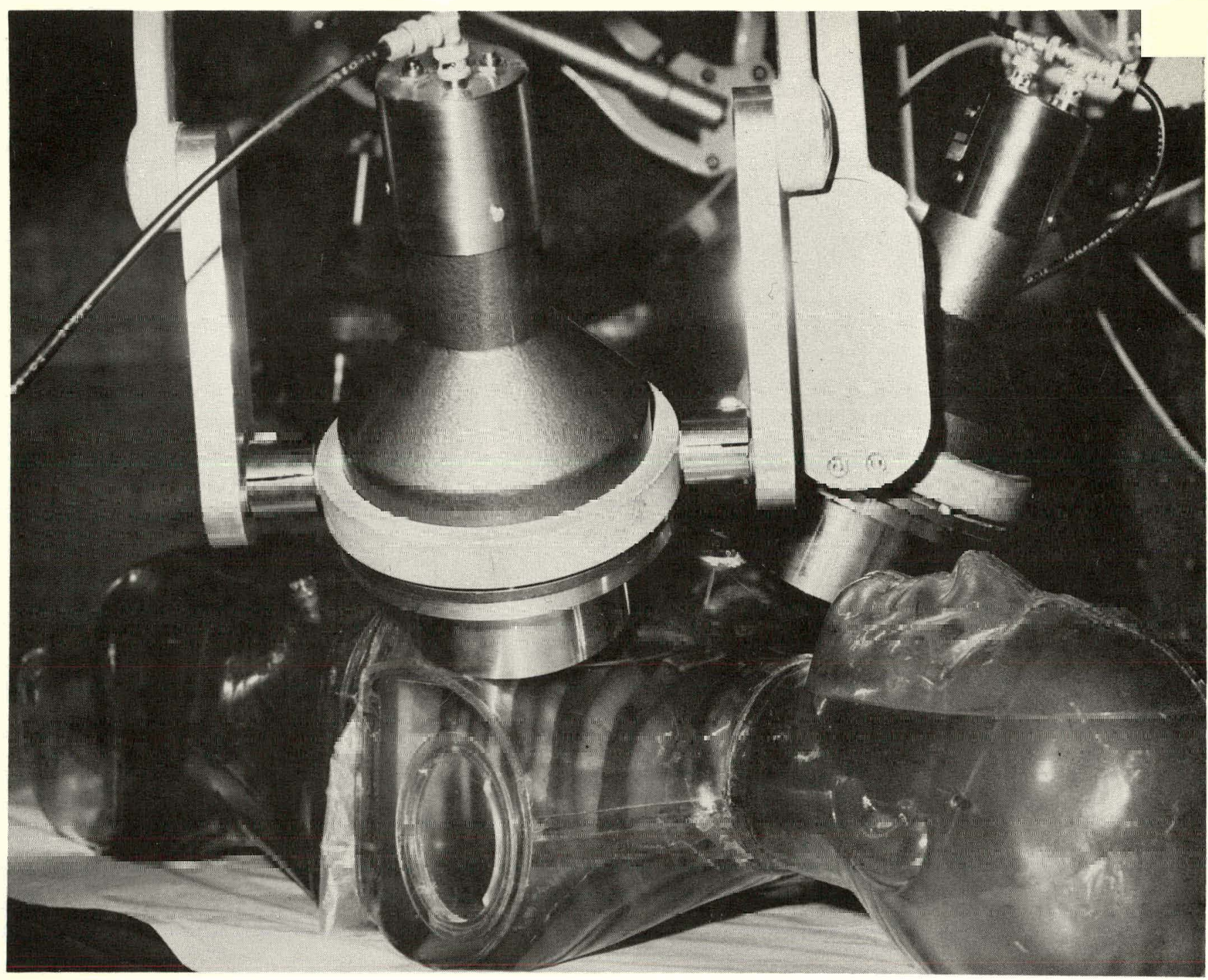

$17262-7$

FIGURE 4. Two Dual Crystal Scintillators in Position Over a Model Phantom.

The configuration uses a pulse-shape analyzer (PSA) to time the crossover period for the linear pulse and produces a linear pulse output for that time period.

The PSA timing range is set to provide an easily discriminated voltage-level output with sufficient separation between the voltage amplitude developed for the $\mathrm{NaI}(\mathrm{Tl})$ crossover time and the longer decay time of the CsI (T1) as shown in Figure 7.

A biased amplifier is used to expand the region of interest and to set the amplitude from $\mathrm{NaI}$ ( $\mathrm{Tl}$ ) crossover to a voltage in the mid range of the integral discriminator used in normal Nuclear Instrument Module (NIM) systems. The voltage output used in both configurations described here is set at approximately 2 volts. A typical biased amplifier output is shown in Figure 8.

The biased amplifier output provides the input signal to a single-channel analyzer (SCA). The analyzer has two variable analog voltage levels that are manually set to bracket the region of linear analog voltage representing crossover time developed 


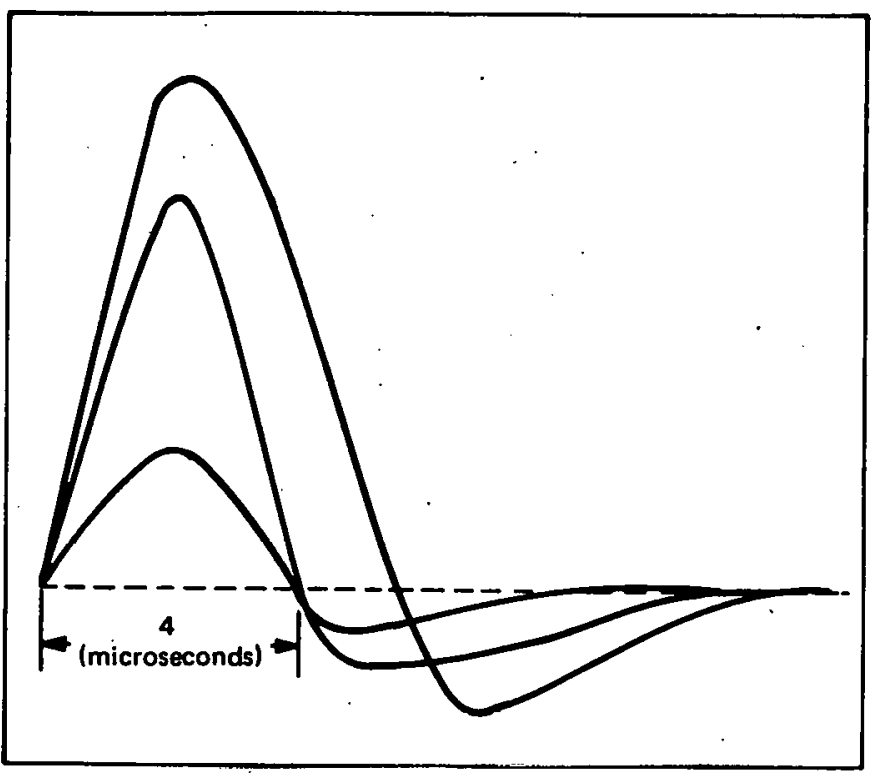

FIGURE 5. Pulse-Shape Outputs of

Delay-Line Phoswich Configuration.

FIGURE 6. Delay-Line Amplifier with Americium-241 Source (Pulse-Time Distribution.)

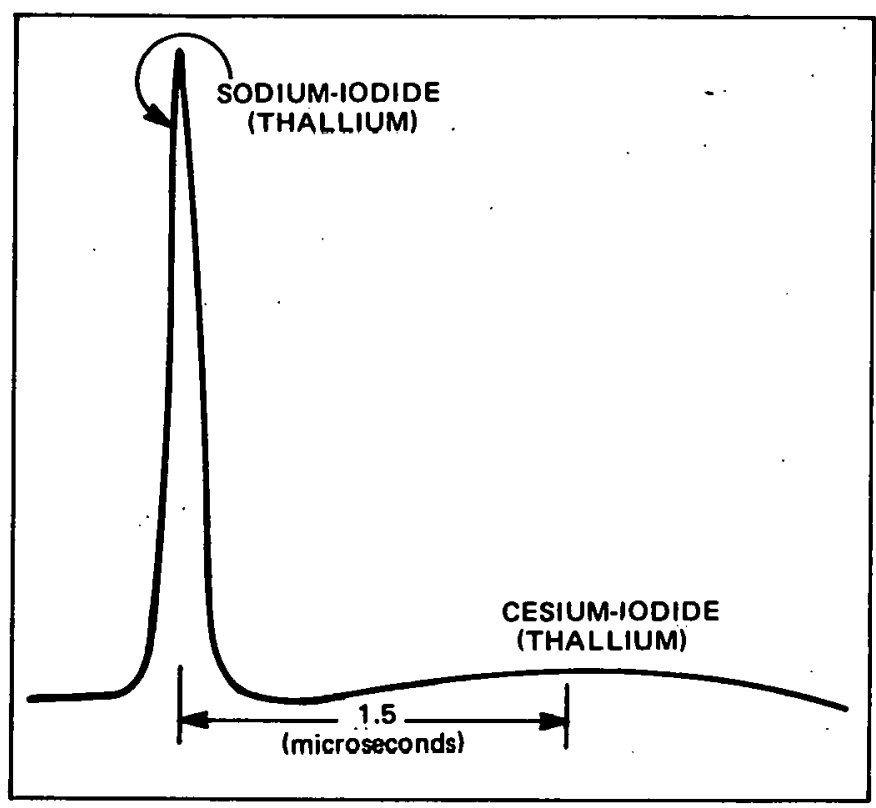

in the PSA. A typical output is a standardized pulse approximately 400 nanoseconds in length (see Figure 9).

During the time the PSA is determining the crossover time of the amplifier pulses, the linear signal voltage is delayed 6 microseconds in a linear delay

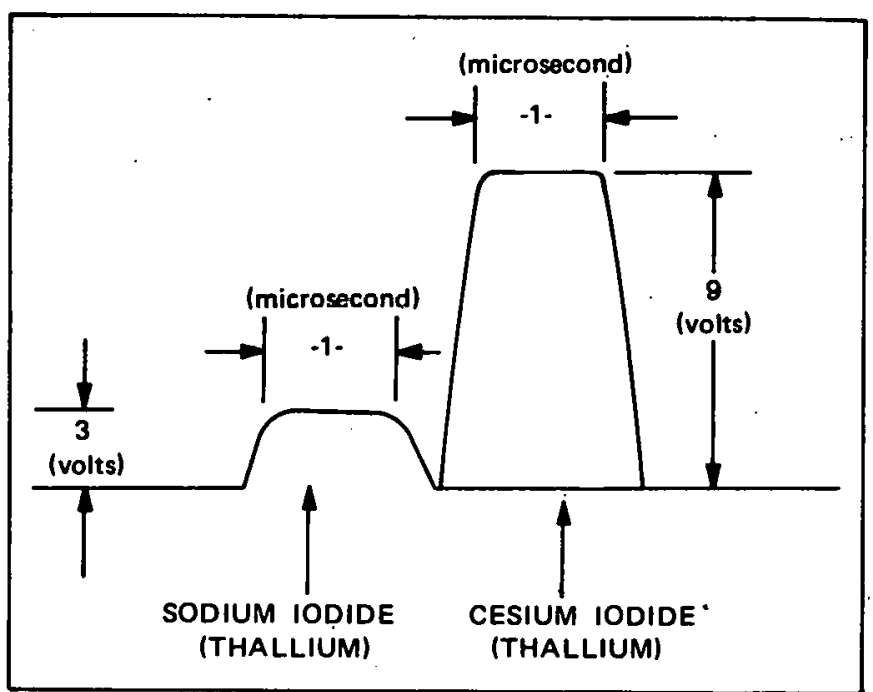

FIGURE 7. Delay-Line $\Lambda$ mplifier: Voltage Output of Pulse-Shape Analyzer (PSA).

FIGURE 8. Delay-Line Amplifier: Voltage Output of Biased Amplifier (Detector No. 1).

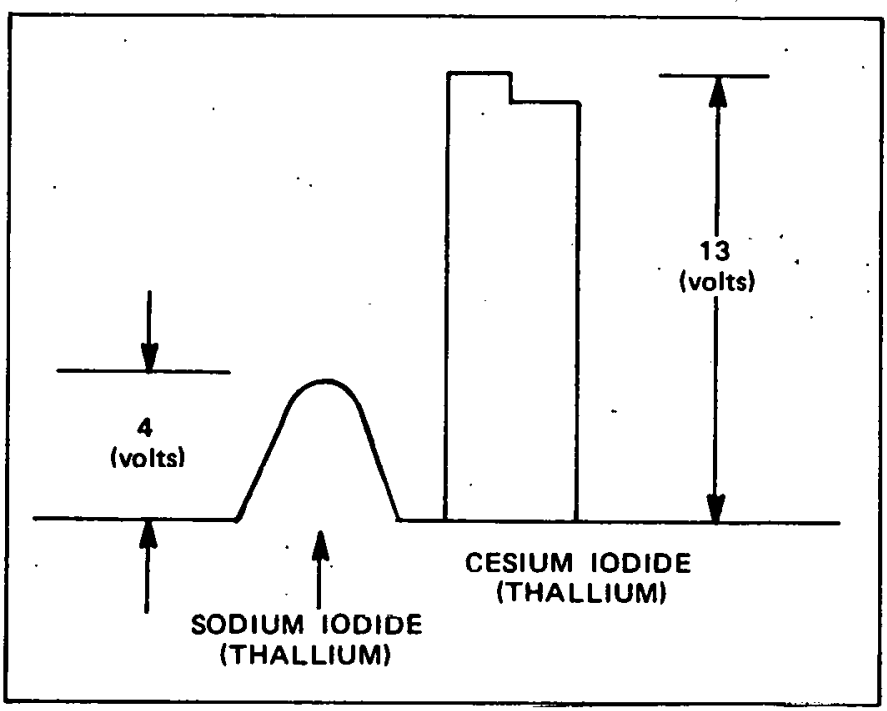

module (see Figure 10). The 6-microsecond delayed pulse triggers an integral discriminator which provides an input to the coincidence module controlling the amplifier output through the linear gate to the PHA mixer shown in Figure 11.

The normalized signal from the single channel analyzer is sent to a gate and delay generator to provide a variable delay for the second coincidence timing to coincide with the normalized signal 


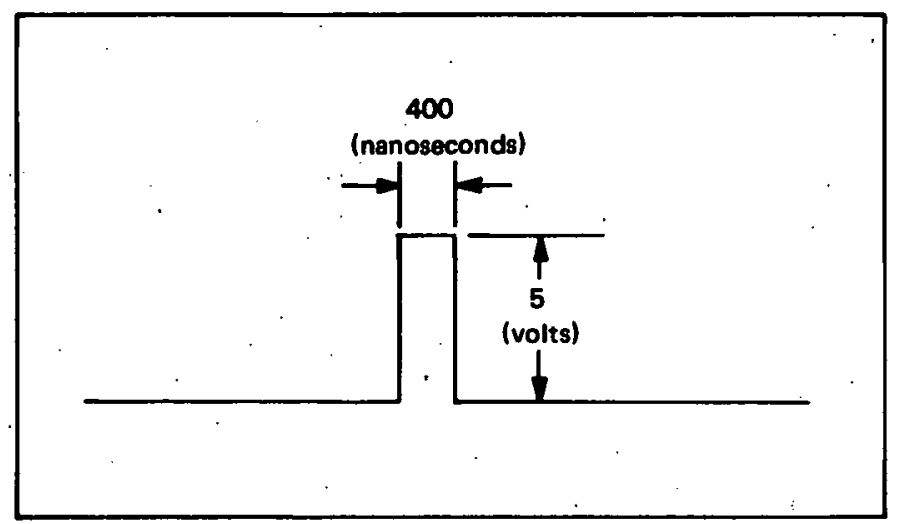

FIGURE 9. Delay-Line Amplifier: Standardized Pulse Output from Single Channel Analyzer (Detector No. 1).

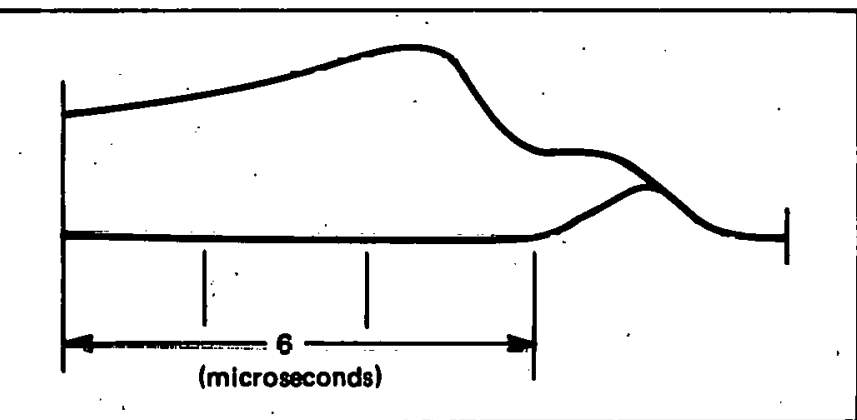

FIGURE 10. Delay-Line Amplifier: Linear Signal Voltage (Detector No. 1).

FIGURE 11. Delay-Line Amplifier: Discriminator to Detector No. 1 Coincidence.

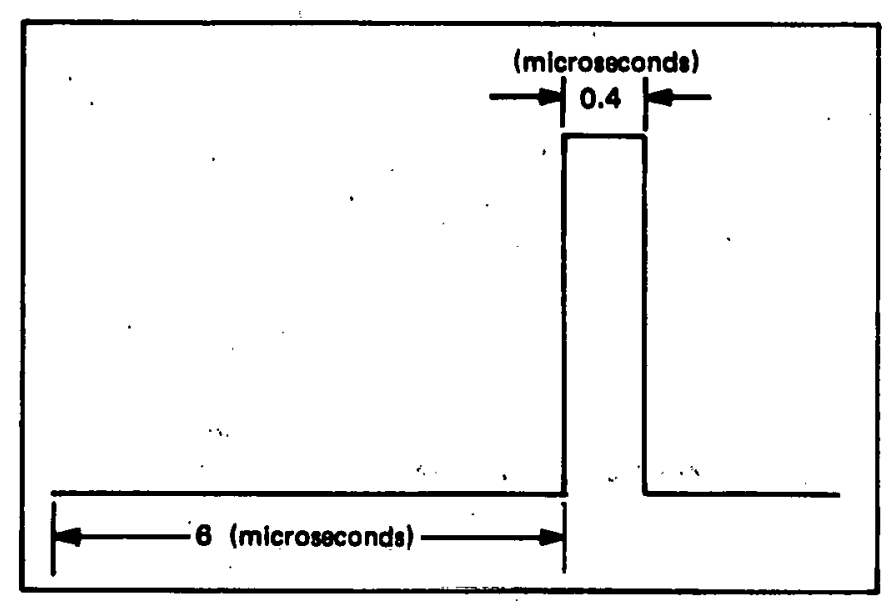

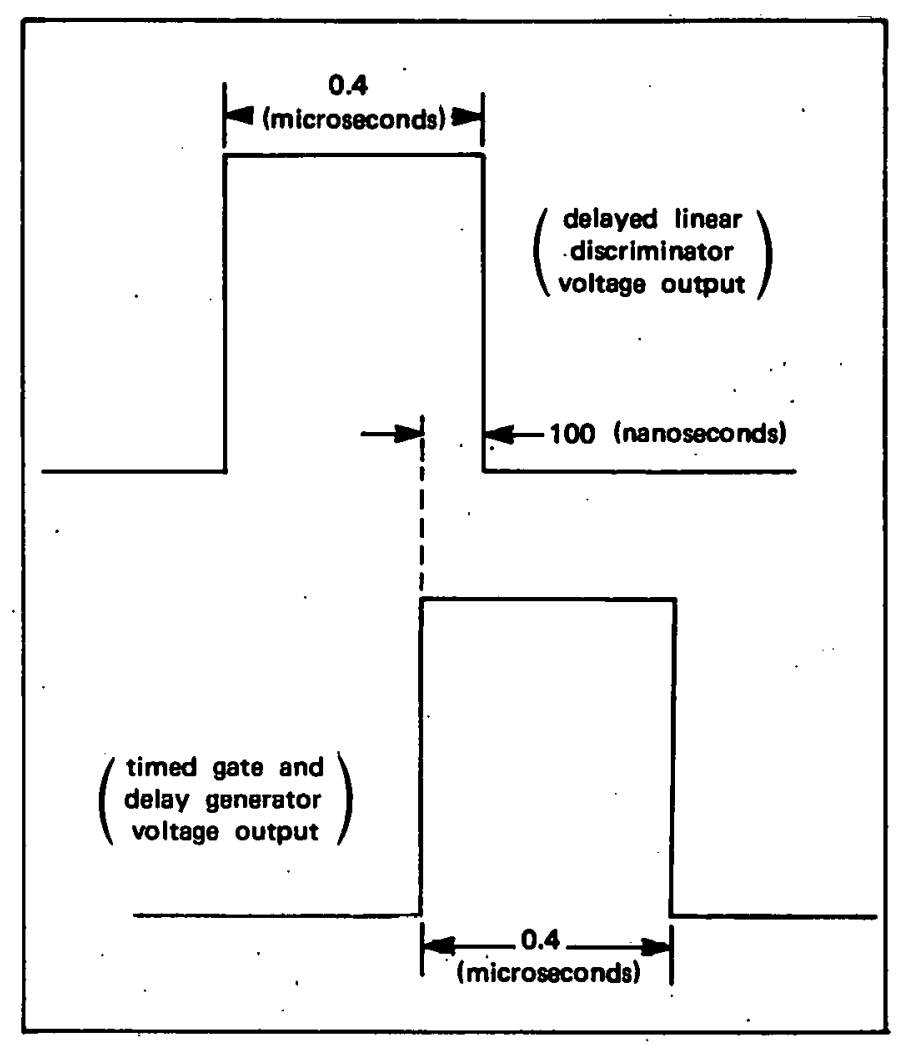

FIGURE 12. Delay-Line Amplifier: Coincidence Timing (Detector No. 1).

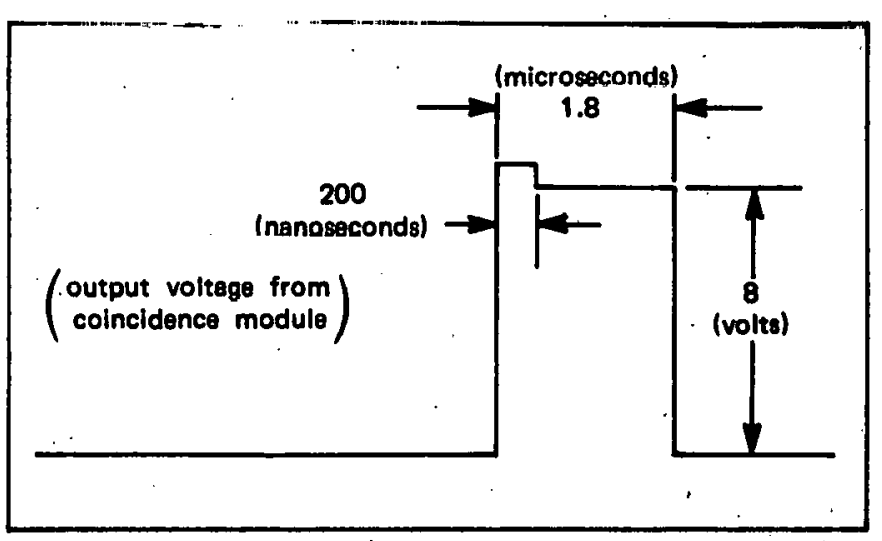

FIGURE 13. Delay-Line Amplifier: Coincidence Timing Output (Detector No. 1).

FIGURE 14. Delay-Line Amplifier: Linear Gate Output (Detector No. 1).

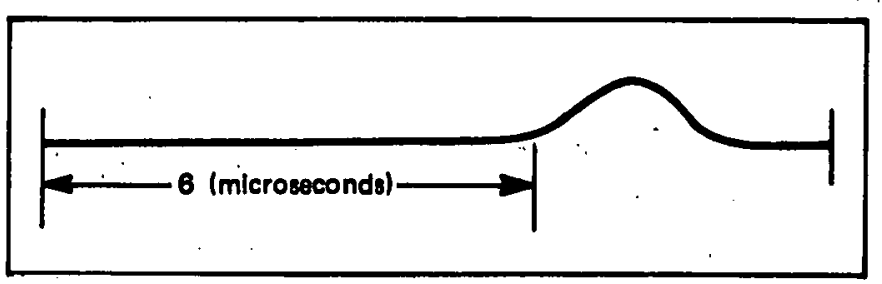


produced from the linear-delay discriminator. The two discriminator signals are coupled to separate inputs in the coincidence module. The delay generator must be adjusted to produce an overlap of 100 nanoseconds as shown in Figure 12. The coincidence output regenerates a 3-microsecond pulse which allows the linear gate to open and allows the linear pulse through the linear gate as shown in Figures 13 and 14. The pulse height analyzer (PHA) is operated in the anticoincidence mode and accepts the linear pulse with its routing signal to set the conversion in the ADC into the proper group.

The block diagram for the delay-line amplifier configuration is shown in Figure 15.

\section{Resistance-Capacitance}

Shaping Amplifier Configuration

The second configuration utilizes a time-to-pulse height analyzer (TPHA) with a timing single-channel analyzer (TSCA).
The configuration uses a resistance-capacitance (R-C) shaping amplifier which develops the pulse distribution shown in Figures 16 and 17 for the decay times from $\mathrm{NaI}(\mathrm{Tl})$ and $\mathrm{CsI}(\mathrm{Tl})$.

Due to the shaping time, constants of the amplifier and decay times produced for the scintillator are longer than those developed by the delay-line amplifier.

The linear signal output from the R-C amplifier is used in several modules to develop the start pulse to the time-to-pulse height analyzer (TPHA), time the crossover in the timing single-channel analyzer (TSCA), and a delay in the linear-delay module until timing is finished.

The pulse outputs to the timing configuration are similar to those developed in the delay line timing circuits. The start-stop pulses to operate the TPHA are shown in Figure 18. The configuration using the $\mathrm{R}-\mathrm{C}$ shaping amplifier and the TPHA is shown in Figure 19.

FIGURE 15. Delay-Line Timing Configuration: A Two-Crystal Scintillator.
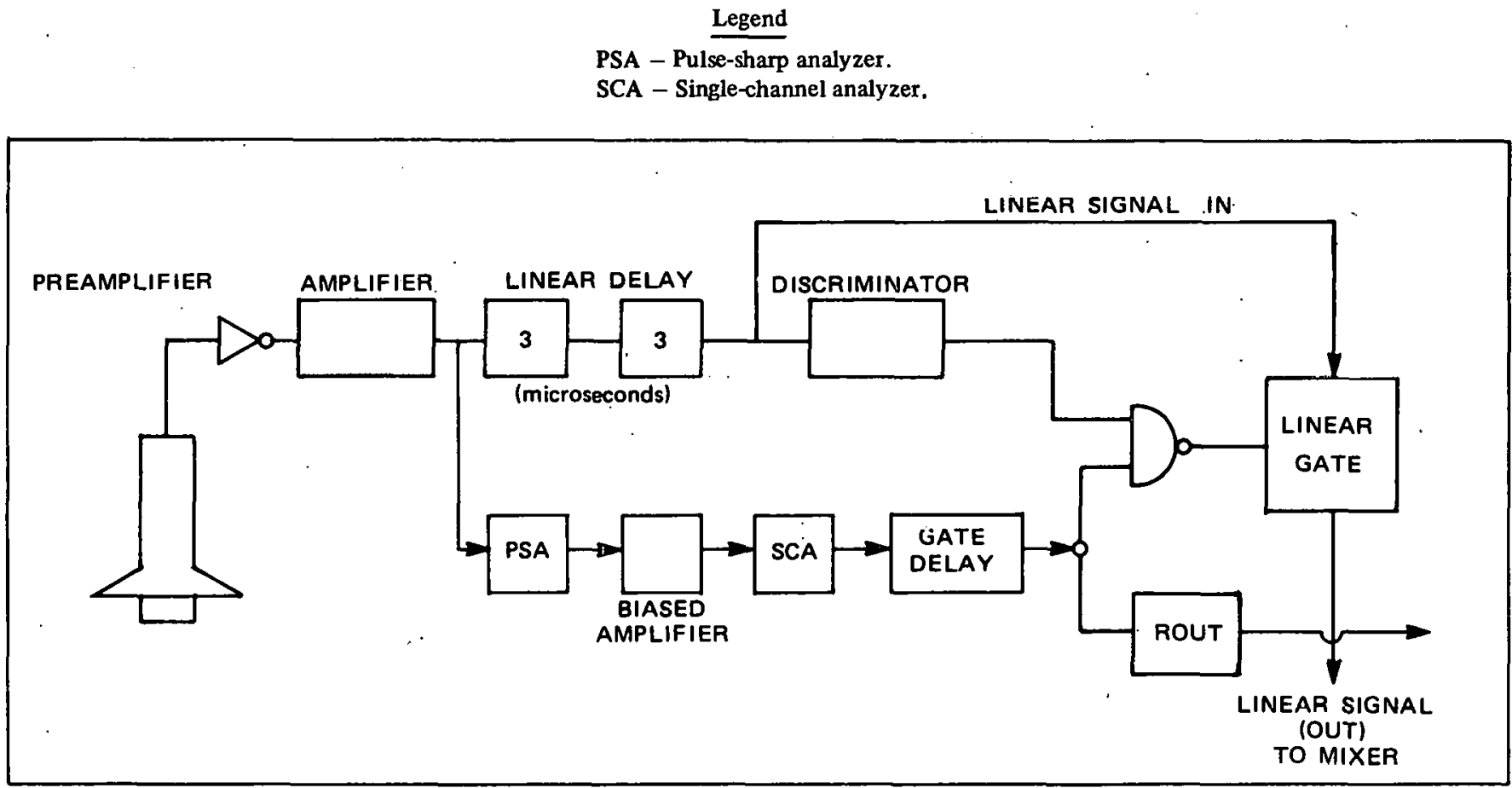


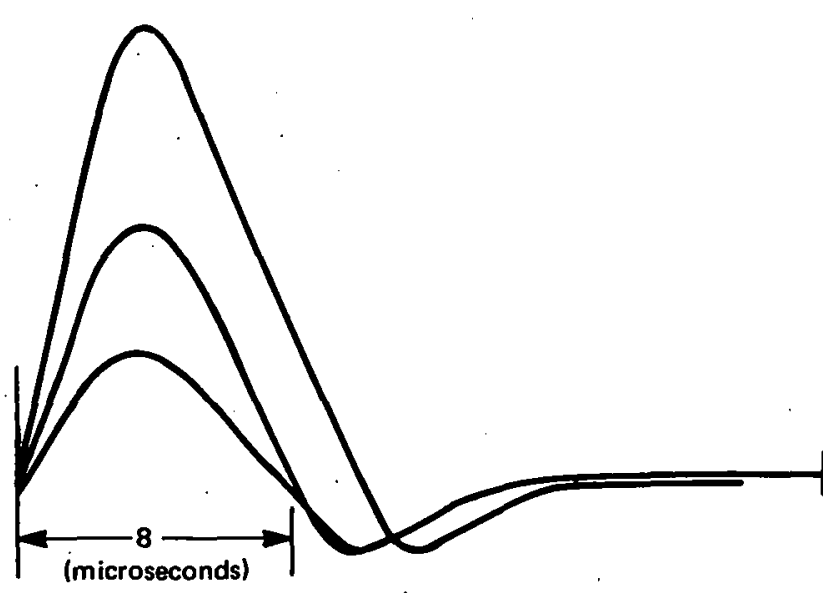

FIGURE 16. Resistance-Capacitance Shaping Amplifier: Pulse Distribution for Detector No. 2.

FIGURE 17. Pulse Time Distribution from Dual Crystal Scintillator Using a Resistance-Capacitance Shaping Circuit with an Americium-241 Source.

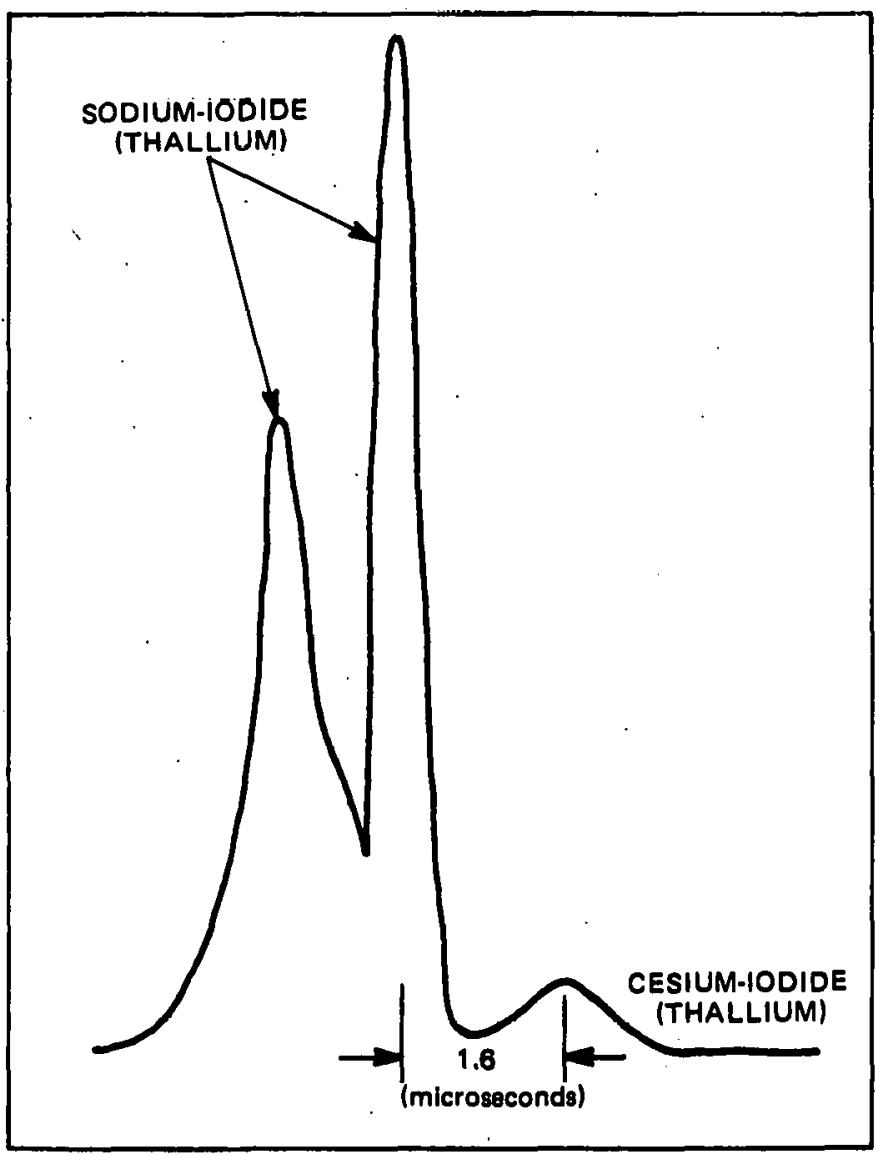

The configuration also includes a gate and delay generator to provide a variable delayed normalized pulse to the coincidence input with the same overlap of approximately 100 nanoseconds as in the delayline configuration.

Provided also is an opened linear gate to allow pulses with the $\mathrm{NaI}(\mathrm{Tl})$ decay time to pass through to the PHA mixer input as shown in Figure 20.

The routing signal to gate the ADC conversion to the proper group of the memory is obtained from the gate and delay generator and regenerated in another integral discriminator.

\section{System Performance--}

The two Phoswich detectors have been used to obtain room background data over the same energy range as uscd for the single 10.16 by $0.4-\mathrm{cm}$ scintillation crystal.

Figure 21 shows the relative room background for two crystal configurations tor a coünting perlod of 2000 seconds.

FIGURE 18. Timing Single-Channel Analyzer Output to Discriminator (Detector No. 2).

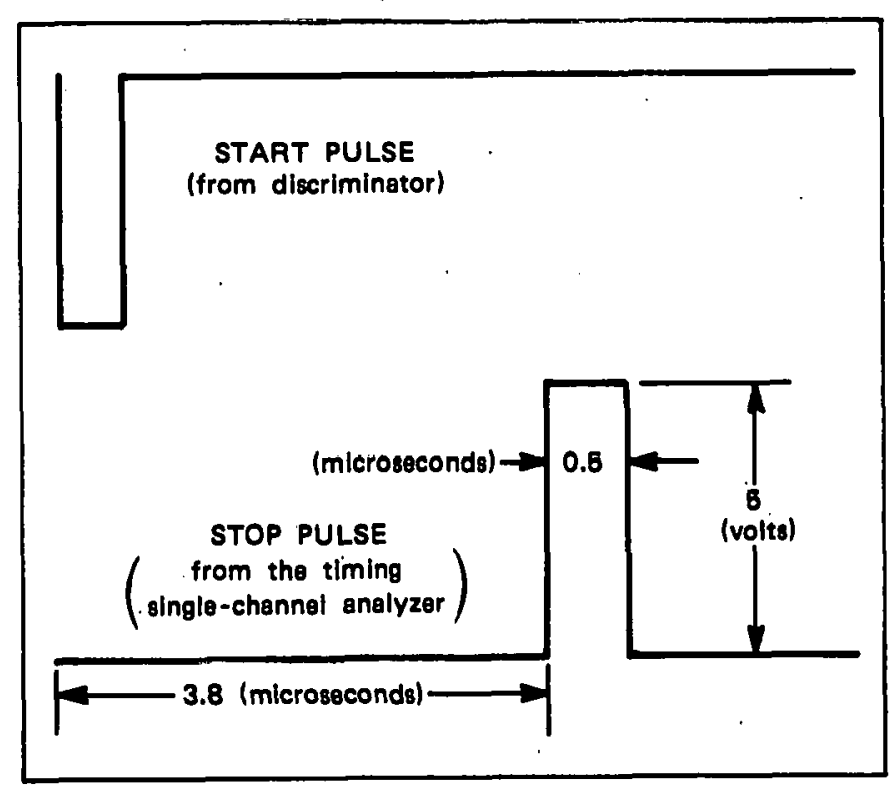




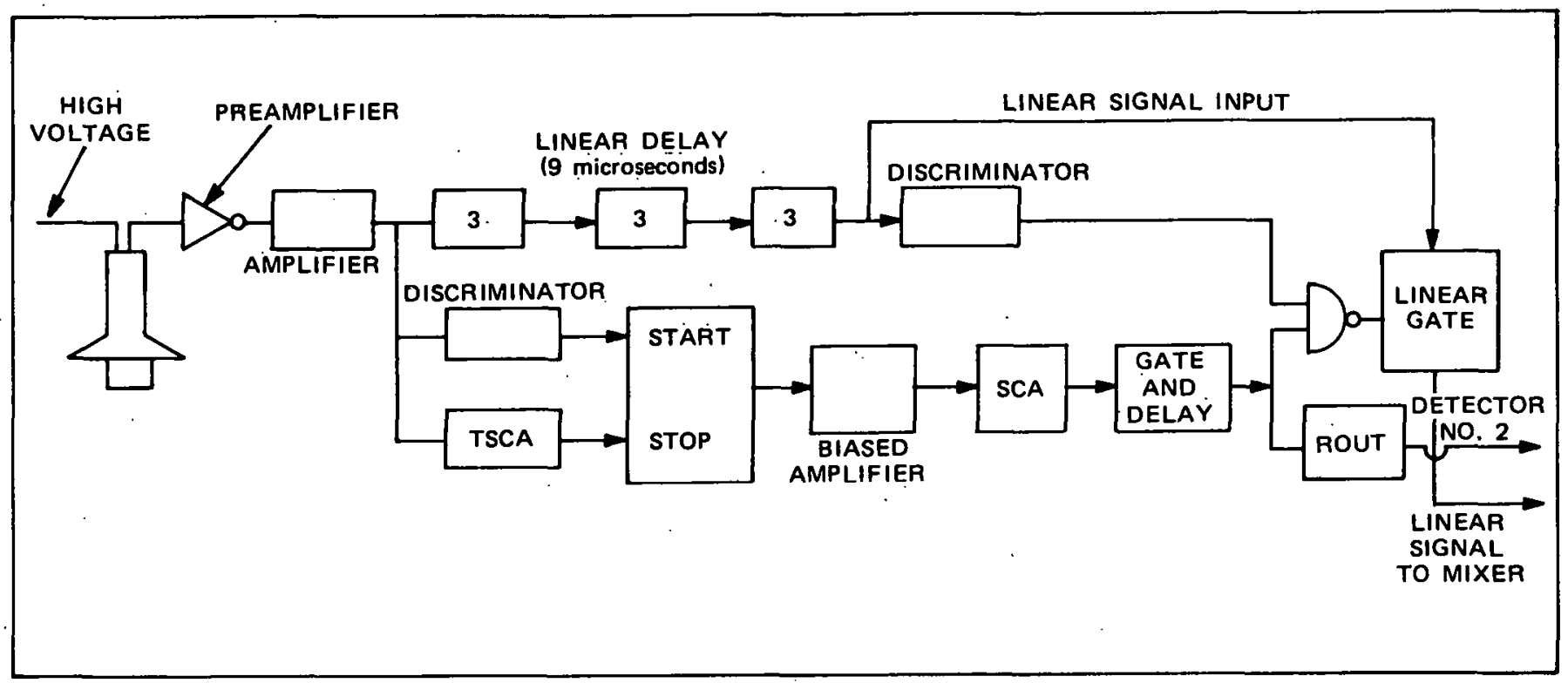

Legend

SCA - Single channel analyzer.

TSCA - Timing single channel analyzer.

FIGURE 19. Resistance-Capacitance Shaping Configuration (Detector No. 2).

A comparison of counting data using a model phantom with background lungs inside the steel room was made with the 4 by 4 -mm single crystal and dual crystal systems. The results of these comparisons are shown in Figure 22.

The two configurations were used to obtain counting data from the phantom loaded with 10-lung burdens of ${ }^{239} \mathrm{Pu}$ with 2000 parts per million (ppm) ${ }^{241} \mathrm{Am}$. Figure 23 shows the resultant data for the two configurations. The counting period was 1000 seconds.

In Table I, comparisons are given of equal integration areas across the energy spectrum used for the background comparison of the single crystal and the Phoswich dual-crystal.
FIGURE 20. Resistance-Capacitance Shaping Amplifier: Linear-Gate Output (Detector No. 2).

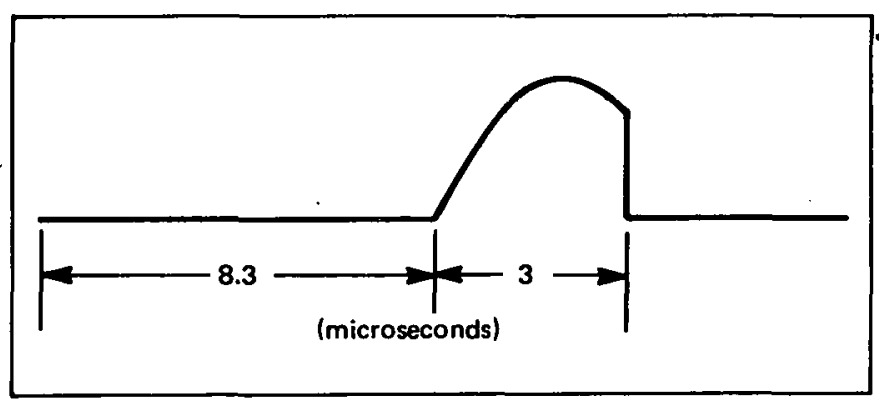

TABLE I. Comparison of Background Data.

\begin{tabular}{|c|c|c|c|c|}
\hline \multicolumn{3}{|c|}{ Single Crystal } & \multicolumn{2}{|c|}{ Phoswich Dual Crystal } \\
\hline Summation of Counts & Right & Left & Right & Left \\
\hline & & & & \\
\hline$\Sigma 17(14$ to 24$)$ & 21.2 & 23.6 & 2.46 & 3.8 \\
\hline$\Sigma 40$ to 75 & 24.2 . & 22.7 & 6.8 & 8.6 \\
\hline$\Sigma 45$ to 65 & 12.9 & 11.9 & 4.2 & 4.7 \\
\hline$\Sigma 85$ to 100 & 12.2 & 13.2 & 1.6 & 2.6 \\
\hline
\end{tabular}


RFP-2136

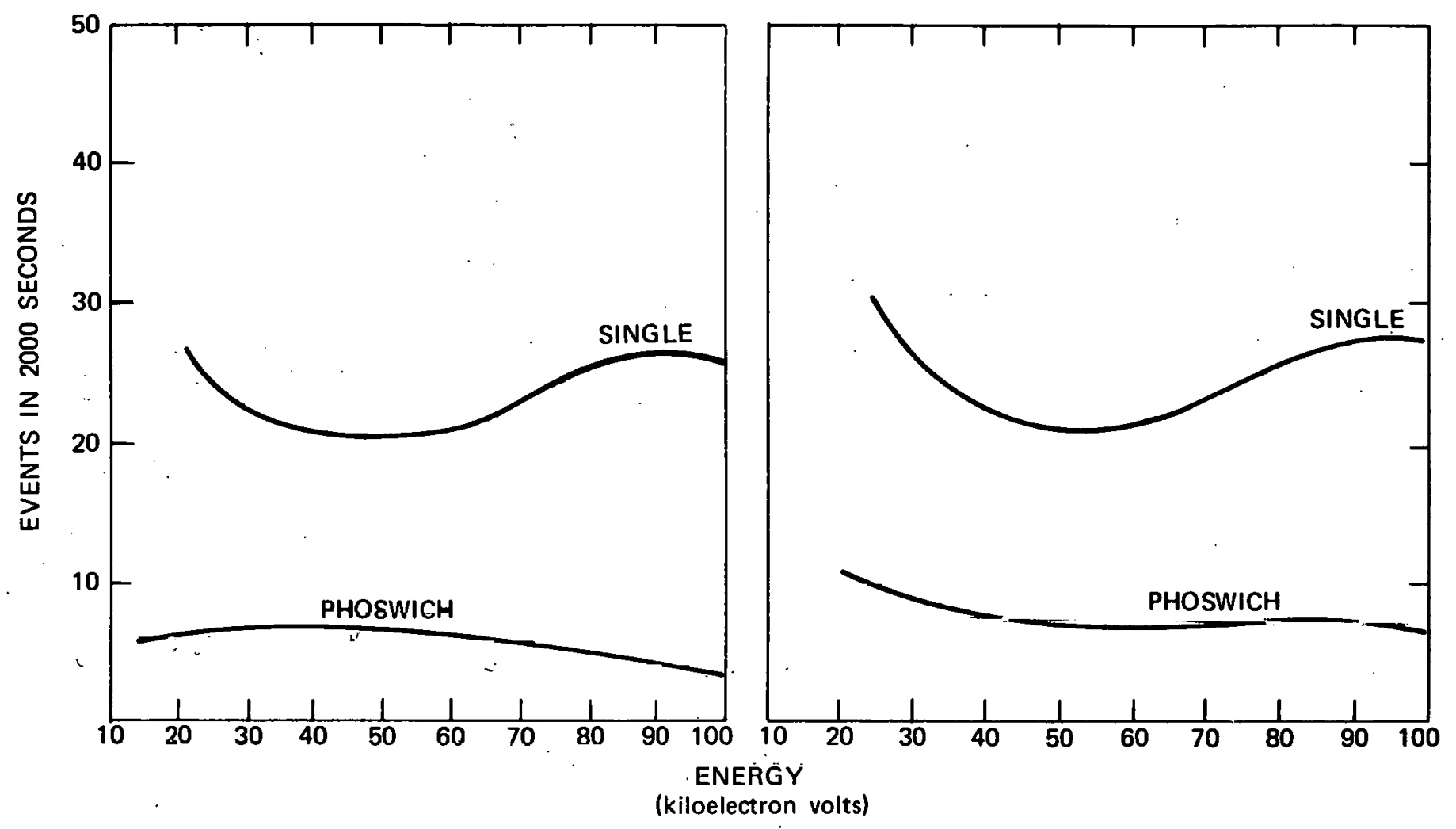

FIGURE 21. System Performance: Room Background Counts.

FIGURE 22. System Performance: Model Phantom Background.

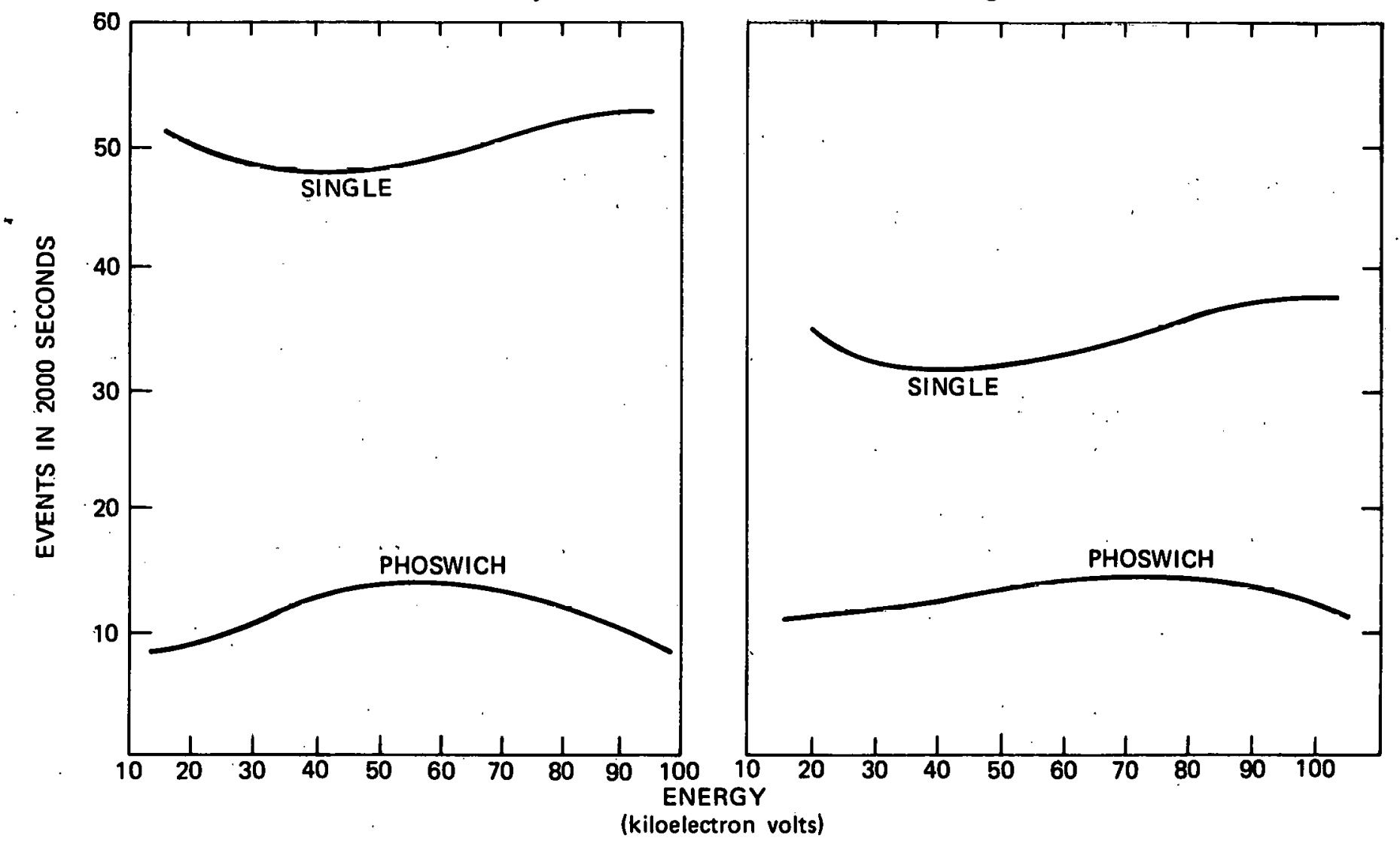




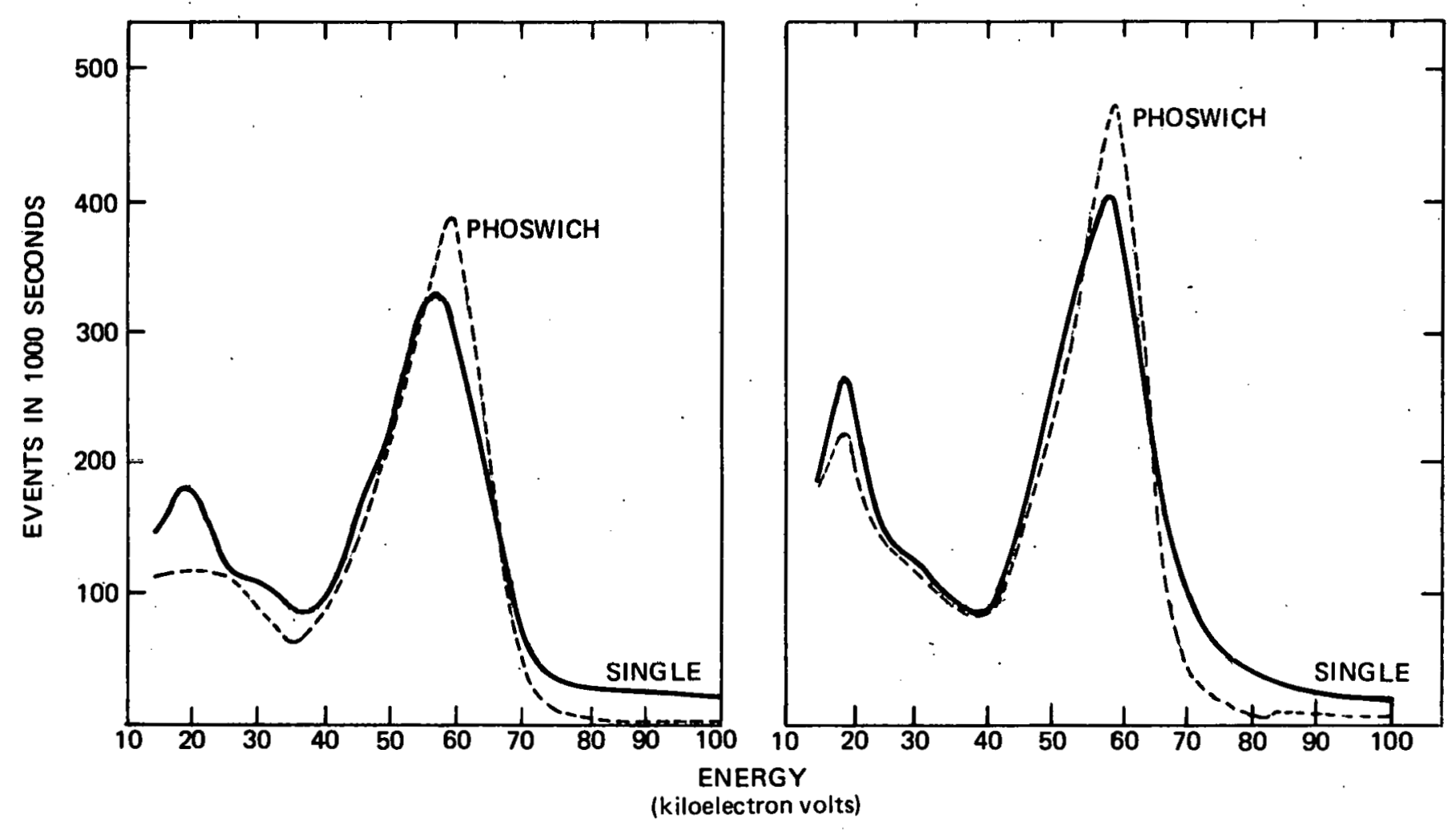

FIGURE 23. System Performance: Model Phantom with Plutonium and Americium. 